\title{
Tarih Yazımında Sınırlandırmalar: Tarihçi İçin Ceteris Paribus*
}

\section{Nuri Adiyeke **}

Öz

Diğer bilimlerde olduğu gibi tarih biliminde de araştırmacının ele aldığı problematiğin sınırlandırmalarını doğru tespit ederek çalışmasını buna uygun olarak yönlendirmesi beklenir. Bu sınırlandırmalar birkaç şekilde düşünülebilir:

I-Yazım amacına göre sınırlandırmalar: Doktora veya kitap çalışmaları, makale çalışmaları, bildiri tebliğ çalışmaları.

II-Kaynak kullanımına göre sınırlandırmalar: Özellikle Osmanlı tarihi ile ilgili birçok çalışma belli bir kaynağa göre yapılmaktadır.

III-Kronolojik sınırlandırmalar: Tarih yazımında en çok rastlanan sınırlama şeklidir. Birçok kez izah edilen sınırlamalara rastlanılsa da kimi zaman hiçbir anlamı olmayan ve tamamen keyfi kronolojik sınırlamalar da görülmektedir.

IV-Olay ve olgulara göre sınırlandırmalar: Problematik olarak tanımlanan konunun analizinde, binlerce değişken/etken faktörün sabit olduğu varsayımı ile hareket edilerek sadece bir değişken analizi esasına dayalı bu çözümleme kuramsal olarak analiz yeteneğimizi güçlendirecektir.

Çalışmamızda yapılamayan sınırlandırmaların oluşturduğu bilimsel problemler; yanlış yapılan sınırlandırmaların oluşturduğu problemler örneklenerek sınırlamalara dair önerilerimiz sunulmaktadır.

\section{Anahtar Kelimeler}

Tarih, tarihçi, metot, sınırlama, ceteris paribus.

Geliş Tarihi: 12 Ocak 2017 - Kabul Tarihi: 09 Mart 2017

Bu makaleyi şu şekilde kaynak gösterebilirsiniz:

Adıyeke, Nuri (2020). "Tarih Yazımında Sınırlandırmalar: Tarihçi İçin Ceteris Paribus”. bilig - Türk Dünyası Sosyal Bilimler Dergisi 94: 123-135.

** Dr. Öğretim Üyesi, Dokuz Eylül Üniversitesi, Edebiyat Fakültesi, Tarih Bölümü - İzmir/Türkiye ORCID ID: 0000-0001-8577-2357

nuri.adiyeke@deu.edu.tr 


\section{Giriş}

Tarihin çok farklı amaca dönük yazım biçimleri vardır. Sadece hoşça vakit geçirtmek için yazılan tarihler, ideolojilere dayanak olması için yazılan tarihler, ders çıkarmak için yazılan didaktik tarihler eski dönemlerden beri geniş bir külliyat oluşturmuştur. Bu amaçlara yönelik yazılan tarihlerin azımsanmayacak kullanıcıları da hep olmuştur.

Tarih yazımının en önemli olanı ise bizce bilimsel tarih yazımıdır. Tarihin bağımsız bir bilim olmayıp muhtelif bilimlerin terkibi olduğu (Bon 1932: 11) tezi günümüzde anlamını yitirmiştir. Bury'nin, tarih bir bilimdir, ne eksik ne fazla sözü (Collingwood 2005: 83) bundan sonra söyleyeceklerimiz için temel düsturumuzdur. Tarih bir bilimdir, tıpkı diğer bilimler gibi. Bilimin belirli veri toplama, araştırma ve çalışma yöntemi vardır. Bilimin belirli bir üslubu vardır ve en önemlisi bilim felsefesi vardır. Bu kavramlar hangi bilim için konuşulursa konuşulsun geçerlidir. $\mathrm{Bu}$ anlamda araştırma süreç ve teknikleri, veri toplama yöntemleri ve işlenmelerinin farklı olmasına rağmen bütün bilimlerin peşinde koştuğu şey aynıdır.

Temel tartısma konumuz, tarih başta olmak üzere bilimsel yöntemler ve yaklaşımlar değildir. Tartışacağımız sorun sadece bilimsel çalışmalarda özellikle de tarih araştırmalarında önemli bir problem olan sinırlandırma sorunudur. Diyalektik ilkelerin en önemlilerinden birisi şudur; her şey birbiriyle ilgilidir. Buna göre; "gerçek bir bütündür. Gerçeğin parçaları arasında karşılıklı etki ve evrensel bir bağımlılık vardır. Doğa, bileşik anlaşılır bir bütündür. Hiçbir olgu onu çevreleyenlerden ayrı tutulunca anlaşılamaz" (Karasar 2000: 19). Bu görüş felsefi olarak doğru ve kabul edilebilir olsa da pratik olarak böyle bir araştırma ve yazım biçimi mümkün değildir.

Bilim seçicidir. Evrende olup biten olgular çeşit ve sayı yönünden sonsuzdur... Bir olgunun bilime veri niteliği kazanabilmesi için ya inceleme konusu bir probleme ilişkin olması, ya da hipotez veya teorinin test edilmesinde kanıt değeri taşıması gerekir. Bu bakımdan bilimsel araştırmaya konu olan olgular, tüm olguların küçük bir parçasını kapsamaktadır. (Yıldırım 2000: 21)

Bu seçicilik aynı zamanda bir sınırlandırmayı da içerir. Tarih tanımı gereği, epistemolojik olarak da pratik olarak da bütünü kapsayıcı olamaz.

Tarihin içerikleri neredeyse sınırsı olduğundan, hiçbir tarihçi 
geçmişteki olayların bütününü kapsayamaz... Geçmişte olanların ancak bir bölümü aktarılabilir ve hiçbir tarihçinin anlatımı geçmişe tam olarak karşılık gelmez. Geçmişin salt oylumu, tek başına bütünsel bir tarihin önünde engel oluşturur. (Jenkins 1997: 23) ${ }^{1}$

Bu durumda tarihçiye düşen görev, "tarih vakıalarının teşkil ettikleri karışılık karşısında tarihçinin tanıması lüzumlu olan ilk zaruret, araştırmalarının sahasına sınır çekmektir." (Langlois 1937: 227).

Sınırlandırılan çalışma probleminin onu etkileyen diğer etki faktörlerinden nereye kadar ayrık olacağı önemli bir tartışma konusudur. Bu sorunun pratik çözümü ancak, bütünün tanımlanmış problem tematiği ile olan ilişkisinin, gerektiği kadarı ile açıklanması ile mümkün olabilir. Aksi takdirde tanımlanmış olan temel problematik, başka deyimle temel araştırma konusu anlaşılamaz bir girift macera ve detay içinde kaybolur gider. Pratik açıdan da ele alınan temel problematiği çevreleyen olguların hepsi konusunda yeteri derecede bilimsel donanıma sahip olmak mümkün değildir. $\mathrm{O}$ halde pratik çözüm, bilimsel çalışmanın sınırlarını net olarak tanımlamaktır. Bu noktadan hareketle bilimsel çalışmaların önemli olmazsa olmazlarından birisi, araştırma konusunun sınırlarının net olarak çizilmesidir. Şu hususu da belirtmek gerekir ki yapılan her sınırlandırma görecelidir. Bugün bu türden sınırlandırma yapılırken gelecekte başka tür sınırlar ve sınıflamalar yapilacaktır.

Konunun sınırlandırılması, epistemolojinin temel sorunlarından birisi olmakla birlikte literatürde bu konu anlatılırken genelde problemin/ problematiğin tanımı veya konunun seçimi başlığı altında "problemin, konunun sınırlandırılması gereklidir” denilip geçiştirilmektedir.

Diğer bilimlerde olduğu gibi tarih biliminde de araştırmacının ele aldığ 1 problematiğin sınırlandırmalarını doğru tespit edip çalışmasını buna uygun olarak yönlendirmesi gerekmektedir. Şunu da belirtmek gerekir ki aslında her çalışma başlığı bir sınırlamayı doğal olarak içermektedir. Türkiye'de yapılan bilimsel tarih çalışmaları incelendiğinde kimi zaman bilinçli kimi zaman da farkında olmadan birkaç grupta sınırlamaların yapıldığı görülmektedir.

I-Yazım amacına göre sınırlandırmalar: Konunun sınırlandırılması, doktora veya kitap çalışmaları, makale çalışmaları, bildiri tebliğ çalışmaları çerçevesinde farklı olmak durumundadır. Doktora ve kitapların büyük 
hacimli çalışmalar olması çerçevesinde konular daha geniş tutulabilmektedir. Sınırlamalar daha az olmakla birlikte yine de vardır ve bu tür çalışmalarda sınırlamalar tarif edilmekte ve çalışmanın dışında tutulan alan ve problematikler tanımlanmaktadır. Buna rağmen özellikle tez çalışmalarında (danışmanların farklı sebeplerle tez ile fazla uğraşıp düzeltmeleri yapamamalarından dolayı) kimi zaman giriş ve konunun tarihsel platformu, tezin kendisi kadar yer tutabilmektedir. Şüphesiz ki tanımlanan temel problematik konuya başka etki faktörleri ve tarihsel bağlam çerçevesinde sadece bağlantı koordinasyonu kadar ilişkilendirilmelidir, daha fazlasınca değil. X konusundaki bir çalışma için çalışma hacminin yarısı veya yarısına yakını konuyu doğrudan ilgilendirmeyen veya dolaylı olarak ilgilendiren detay ve tarihsel bağlama harcanmamalıdır.

Temel problematik olarak tanımlanmış çekirdek konunun dışındaki konular kurgulanan metne ancak "gerektiği kadar" monte edilmelidir. Aksi takdirde, Osmanlı İmparatorluğu ile ilgili her çalışma, Osmanlı Beyliği’nin kuruluş öyküsü ile başlamak durumunda kalır.

Makale yazımları için de benzeri bir durum söz konusudur. Ne var ki makaleler daha spesifik konulara yönelen daha küçük metinler olduğu için konu sınırlandırmasının çok isabetli yapılması mecburiyeti vardır. Konunun spesifik olması metnin de daha az sayfaya sığdırılması bu tür yazımlarda sınırlandırılmış olan detay konuyu geniş çerçeveye oturtmayı zorlaştırmaktadır. Bazen bu tür yazılarda da olması gerektiğinden daha uzun bir giriş, uzun bir tarihsel boyut karşımıza çıkabilmektedir. Kimi zaman da detay konu bütün ile ilişkilendirilmeden çalışma sonlandırılmaktadır.

Metinler itibarıla en yoğun problem bildirilerde görülmektedir. Ulusal olsun uluslararası olsun bir çok sempozyum ve kongrelerde konuşmacılara genelde yirmi dakika süre tanınmaktadır. Konuşmacıya ayrılan bu süre içinde temel problematik tanımlanıp gerekli açıklamalar yapılmalıdır. Ne var ki, birçok konuşmacı kendilerine tanınan sürenin çok büyük bir kısmını genel çerçeveye veya bilinenlere ayırarak süresinin birkaç dakikasını ancak yeni ve problematik edilen konuya ayırabilmektedir. 2015 Eylül ayında Kuşadası'nda düzenlenen Girit Tarihi ile ilgili bir sempozyumda ${ }^{2}$ çok sayıda bildiri Girit'in fethi ile başlamıştı. Hâlbuki 19. yüzyıldaki Girit ile ilgili herhangi bir problemi izah etmek için Girit'in Osmanlı’ya katılma hikâyesini bilmeye ve anlatmaya hiç ihtiyaç yoktur. 
Bir başka örnek, 18. yüzyılda Kıbris'taki avarız haneleri konusu anlatılırken, uzun bir Kıbrıs tarihine ve Kıbrıs'ın Osmanlılara nasıl katıldığının hikâyesine hiç gerek yok. Bu bilgiler herhalde bir ya da iki cümle ile geçilmesi gereken bilgilerdir. Yine böylesi bir başlık altında uzun uzun Osmanlı vergi sisteminin ve bu sistem içinde avarız vergilerini anlatmanın da hiç gereği yoktur. Bu metin içinde Osmanlı vergi sistemi bir iki, avarız vergisi de üç beş cümle ile özetlenmelidir. Her iki bilgi kümesi de ancak giriş niteliğindedir ve yirmi dakikalık konuşma metninin ${ }^{3}$ birkaç dakikasını ancak işgal etmelidir. Bu tür toplantılar genelde meslek erbabının katıldığı bilim adamlarından oluştuğu için dinleyiciler hem Kıbrıs tarihini hem de Osmanlı vergi sistemini ve avarız vergilerini zaten bilmektedir. Nitekim böyle bir bildiriyi dinlemeye gelenlerin kafasında, 18. yüzyılda Kıbrıs'ın avarız şekillenmesi nasıldı? Kaç tane avarız hanesi vardı? Her avarız hanesi kaç gerçek haneye tekabül ediyordu? Avarız vergileri çerçevesinde 18. yüzyıl Kıbrıs'ında yaşanan sorunlar nelerdi? Gibi birçok soru vardır. Ne var ki konuşmacının yirmi dakikalık vaktinin on beş dakikasını yukarıda belirttiğimiz herkesin bildiği genel bilgilerle doldurduğu için temel problematik sorularına vakit kalmamakta, bilinmesi ve tartışılması gereken sorunlar tartışılamamaktadır. Yapılamayan sınırlandırma çalışmayı kadük bırakmaktadır.

Bildirilerde yaşanan bu sorunu aşmamın iki yolu vardır. Birincisi konu sınırlamasını çok iyi yaparak yazılı metni 7-8 sayfada tutmaktır. Bu durumda konunun girişi olarak düşünülen genel çerçeve bağlantıları metin dışı bırakılmalıdır. İkinci yöntem ise yazılmış geniş metnin okuma sırası için 7-8 sayfalık konuyu çok iyi izah eden özetinin hazırlanmasıdır.

II-Kaynak kullanımına göre sınırlandırmalar: Özellikle Osmanlı tarihi ile ilgili birçok çalışma belli bir kaynağa göre yapılmaktadır. Şüphesiz dönemlere göre belli kaynak gruplarının yoğun kullanımı kaçınılmaz ise de; tek tip kaynağa dayalı; Tapu Tahrir Defterlerine Göre... / Temettuat Defterlerine Göre... / Kadı Sicillerine Göre... / ...Gazetesine Göre...gibi çalışmalar ciddi eksiklikleri doğurmaktadır.

Bu sınırlandırma doğası gereği coğrafi bir sınırlandırmayı da gerektirmektedir. Çünkü defterler kimi zaman eyalet kimi zaman sancak, kaza hatta köy ve mahalle esasına göre hazırlanan defterlerdir. Tapu tahrir defterleri Osmanlı İmparatorluğu için modern dönemler öncesi kayıtlarıdır. Tımar, vergi, üretim eksenli bu defterler dönemi için çok önemli veriler sunmakla birlikte 
bu amaç için düzenlenmiştir ve yazıldığı dönem için de yazıldığı coğrafya için de her şeyi izah edemez. Keza temettuat defterleri için de aynı şey söz konusudur. Osmanlı'nın Tanzimat döneminin hemen sonrası için (18401845) yazıldığı birimin üretim araçlarını, zenginlik kaynaklarını, meslekleri ürünleri, gelirleri, nüfus yapısını, isimleri gibi birçok konuda geniş veriler sunmaktadır. Ama gerek tahrir defterleri gerek temettuat defterleri kayıtlı coğrafyanın bütünsel izahını yapamaz. Bu tür kaynakların kullanım problemleri ve çokça yapılan yanlışlar çalışmamızın dışında tutulmuştur.

Kadı sicilleri veya yukarıdaki defterler çerçevesinde sadece bu kaynakların cevaplayabileceği sorular sorularak yapılan analizler bir sınırlama olarak kabul edilebilir bir durumdur. Keza, falan seyyaha göre filan konusu veya problematiği ancak seyahatnamelerin taraflılı̆̆ı, seyyahın algı kapasitesi gibi eleştirisi ile kabul edilebilecek bir sınırlama ögesidir.

Kaynak sınırlamasıyla yapılan bir başka çalışma biçimi de bir gazeteye dayalı araştırmalardır. Osmanlı İmparatorluğu’nda, XIX. yüzyılın son çeyreğinden itibaren yaygınlaşan gazeteler kimi zaman bir çalışmanın temel kaynağ olarak kullanılabilmektedir. Tanin Gazetesine Göre X Konusu başlıklı bir çalışma, X konusundan ziyade Tanin Gazetesini esas alan bir çalışma olarak kabul edilmelidir. Böyle bir çalışmada da Tanin Gazetesinin X konusundaki taraflılı̆g 1 veya tarafsızlığı, aynı konudaki tutumu ve yetkinliği de bu çalışmada önemli bir handikaptır.

Osmanlı tarih yazıcıllı̆ıında sıkça karşılaştığımız kaynak esaslı yazım sınırlandırması belki de Türk tarih yazıcılığındaki en problemli alanlardan birisidir ve çok rastlanılan bir durumdur. Geleneksel hale gelmiş bu tür sınırlamaların yarattığı olumsuzluğu gidermenin tek yolu da konunun diğer kaynaklarla desteklenerek işlenmesidir.

Farklı bir başlık altında da incelenebilecek olan bir sınırlama da literatür kullanımında görülmektedir. Maalesef biraz ülkemize has bir durum olan bu konuda, araştırmacı kendi hayat görüşünün dışında olan tarihçilerin çalışmalarını görmezden gelmektedir. Kimi zaman kendi hayat görüşünde olmayan bir araştırmacının çalışmasını bilmeme cehaletinden, kimi zaman da onu kullanmaktan farklı kaygilarla imtina etmesinden kaynaklanan, bilimsel bir çalışma için hiçbir şekilde kabul edilemeyecek olan bir literatür sınırlandırması ortaya çıkmaktadır. 
III- Kronolojik sınırlandırmalar: Genel olarak tarih yazımında en çok rastlanan sınırlama şeklidir. Çoğunlukla kabul gören ve izah edebilen bir sınırlandırma şeklidir. Tarihsel çağ kavramının kabul edilebilen kronolojik bölümlenmesinin yanı sıra ona yapılan çok ciddi itirazların paradoksu Türk tarihçisinin de kafasını karıştırmıştır. Üniversite kürsülerinde hala, bir Osmanlı tarihçisi için sorun oluşturan, ortaçağ, yeniçağ, yakınçağ anabilim dalları bulunmaktadır. Bu ana bilim dalları birbirlerinden kimi zaman o denli uzaktır ki sanırsınız tamamen farklı bilimler. Oysa artık Osmanlı tarihini bir bütün olarak incelemenin zamanı çoktan gelmiştir. Bir tarihçinin hem kuruluş dönemi kaynaklarını ve problemlerini hem de 19. ve 20. yüzyıl kaynak ve problemlerini aynı ölçüde bilmesi beklenemez ama 18. yüzyıl problematikleri ile uğraşan bir Osmanlı tarihçisi bilim adamının 19. yüzyılı bilmesi doğaldır. Dolayısıyla birbirlerinin yüzlerine kapılarını kapatmış bu kronoloji esaslı anabilim dalı uygulaması bazen anlamsız olmaktadır.

Genel yaklaşımımızı kaplayan bu sınırlandırma birçok kez bilimsel çalışmalarda da karşımıza çıkabilmektedir. Kimi zaman bu sınırlandırma anlamlı olabilmektedir. Osmanlı Kurulus Döneminde X Problemi/Kurumu gerçekten anlamlı bir kronolojik sınırlandırma olabilmektedir. Çünkü Fatih Sultan Mehmet döneminden itibaren Osmanlı’nın artık kurumsal olarak çok farklı bir döneme girdiğini biliyoruz. Keza aynı şeklide anılan X probleminin klasik dönem, klasik sonrası dönem, modern dönem sınırlamaları anlamlı izah edici sınırlamalar olarak kabul edilebilir. Osmanlı'daki bir kurumun kuruluşundan yıkılışına kadar olan dönem de incelenebilir. Fakat bu her zaman için mümkün olmayabilir. $\mathrm{O}$ zaman anlamlı bir kronolojik sınırlandırma incelenen kurum ile yukarıda örneklendiği gibi çakıştırılabilir (Kütükoğlu 1998: 31). Burada önemli olan kronolojik sınırlandırmanın bilimsel olarak izahının yapılabilmesidir. Nitekim birçok kez izah edilen, anlamlı sınırlamalara rastlanılsa da kimi zaman hiçbir anlamı olmayan ve tamamen keyfi kronolojik sınırlamalar da görülmektedir.

Burada bir tehlike de kent tarihi çalışmalarında ortaya çıkmaktadır. Amatörlerin hazırladığı, Geçmişten Günümüze X Şehrimiz türü çalışmaların dışında kimi zaman bilimsel çalışmalarda da benzeri problemler görülmektedir. Örneğin; Menemen Kazası 15-18. Yüzyıllar başlıklı bir doktora tezi sanırım yanlış bir kronolojik sınırlandırmadır. Bir kazanın dört asırlık öyküsünü anlatmak ve bunu bir doktora çalışması kapsamında tezleri 
ve hipotezleri ile izah etmek, farklılaşan kaynakları incelemek gerçekten insanüstü bir gayret ve bilgi donanımı gerektirmektedir.

Kronolojik sınırlandırmalar yukarıda da belirtildiği gibi çalışma konusunun gerekleri çerçevesinde, net olarak izah edilebilir şekilde yapılmalıdır. Burada dikkat edilmesi gerek konu, sınırlandırılan dönemin öncesi ve sonrası dönemler ile ilişkisinin gerektiği kadar ve sarih bir şekilde açıklanmasıdır.

IV-Olay ve olgulara göre sinırlandırmalar: 20. yüzyıla kadar tarih, önderlerin ve devletlerin kahramanlık destanı biçimindeydi. Yirminci yüzyılın başlarından itibaren önce sıradan insan, daha sonra da sıradan olan her şey tarih yazımının konusu oldu. Eski dönemlerdeki bir tarihçi için asla konu edinilemeyecek olan bir olgu, günümüz tarihçisi için temel araştırma problematiği haline gelmiştir. Tarihçinin ilgi alanlarındaki bu denli farklılaşma tarih yazımında da yeni düşünce biçimlerini, yeni sorunları ortaya çıkarmıştır. Günümüz tarihçisi seleflerinden farklı olarak mikro olaylarla ilgilenmeye başlamıştır. Bu çerçevede belgelerin konuşma cesareti verebildiği minik bir olay veya herhangi bir olgu tarihçi için artık bir çalışma konusudur. Bu noktada tarihçinin önemli problemlerinden birisi çalışma konusu olan olay veya olguyu net olarak tanımlaması ve sınırlandırmasıdır.

Günümüzde olduğu gibi tarihte de her olay ve olgu onu belirleyen binlerce başkaları ile ilişkilidir. Ne var ki ele alacağımız problematiği betimleyen bütün etki faktörlerinin açıklanması birçok kez mümkün olamayacaktır. $\mathrm{Bu}$ durumda tarihçi için önerimiz birçok sosyal bilimde (özellikle iktisat biliminde) yoğun olarak kullanılan ceteris paribus önerisidir. Latince bir kelime olan ceteris paribüs, "diğer tüm durumlar sabitken” veya "öteki koşullar değişmediği sürece" anlamı taşımaktadır (Eğilmez 2002). Problematik olarak tanımlanan konunun analizinde, binlerce değişken/etken faktörün sabit olduğu varsayımı ile hareket edilerek sadece bir değişken analizi esasına dayalı bu çözümleme kuramsal olarak analiz yeteneğimizi güçlendirecektir.

Tüm bilimlerdeki ceteris paribus için yapılan itiraz (Reutlinger-Unterhuber 2014, 1703 vd) tarih bilimi için daha etkili bir eleştiriyi peşin sıra getirecektir. Ceteris paribus, farzedilen ve kuramsal bir izahtır. En çok kullanılan iktisat biliminde dahi gerçek hayatı izah edemez. Çünkü analiz edilen olaydaki birçok etki faktörü gerçek hayatta değişmeden öylece kalmaz. Onlar da değişir. Bu durumda sizin ceteris paribus ile izah ettiğiniz olay veya olgu pratik hayatın bir sonucu değildir. 
Ceteris paribus için yapılan bu eleştiride haklılık payı olmakla birlikte, bilimin temelinde, ele alınan temel problematiğin soyutlanması vardır. Başka bir deyimle, bilim zaten beyindeki soyutlama faaliyetidir. Bütün bilimlerin çalışma biçimlerinde, soyutlama, problem üretme özelliği vardır. Burada Türk tarihçiliğinin en önemli sorunlarından birisi ile karşılaşıyoruz. Ülkemizde yapılan ve kapağında tez olduğu yazılan binlerce tarih doktora çalışmasının gerçek anlamda bir problematiği yani tezi yoktur. Çalışma bir olayın veya olgunun hikayesini yazmakla başlar ve biter. Tez oluşturabilmek için, incelenen binlerce belgeden problemler üretmek gerekir ki bu da ciddi bir matematik düşüncesini gerektirir. Matematik bilinmeden bilim yapılamaz. Çünkü bilim soyut düşünmeyi gerektirir. Tarih yazarken (bilimsel bir yazım kastediliyor) okunan belgelerden tıpkı matematikçinin yaptığı gibi problemler üretilmesi gerekir, devamla bu problemlerin farklı çözüm yollarının tanımlanması gerekmektedir. Buradan şu noktaya geliyoruz ki bilimsel uğraşının temel hareketliliğinde illa da hayatın pratikleri olmak zorunluluğu yoktur. Teorik fizikle uğraşan bir bilim adamının çalışma problematiklerinin güncel yaşamda karşılığının aranması pek akılcı değildir. Çalışma konusunu kendisi sınırlayan bilim adamı, ceteris paribus sınırlamasını da belirleme hakkına sahip olmalıdır. Burada unutulmaması gereken nokta, hem konusunu sınırlayan hem ceteris paribusunu net bir şeklide tanımlayan tarihçinin ele aldığı olay/olguyu betimleyen başka etki faktörlerinin varlığını inkâr etmeden, başka kombinezonların başka sonuçlar da doğurabileceğini unutmamasıdır.

Bir sınırlandırma biçimi olarak ceteris paribusun tarih yazıcıllğına uygulanmasını somut bir örnekle açıklayalım. Tanzimat dönemi Osmanlı yol politikalarının askeri önemi başlıklı bir çalışmada aslında tanımlanmış bir ceteris paribus vardır. Tanzimat döneminde Osmanlı yönetimi çok ciddi bir yol yapımı gerçekleştirmiştir. Burada temel amaç coğrafya üzerinde ekonomik bağlantı teminidir. Yanı sıra modernizmin bir şekillenmesi olan iletişimin sağlanması, idarenin kolaylaşması, güvenlik vs. gibi birçok sebep yol yapımı politikalarını belirlemiştir. Bu örnek çalışmada politikanın sadece askeri sebepleri ve önemi ele alınmış, ancak diğer faktörler ve politikalar da yok sayılmamıştır. Diğer faktörler ve politikalara bu çalışmada gerektiği kadar yer verilmiştir. Zira bu andan itibaren tanımlanmış bu sınırlandırma sadece askeri etkiler ve politikalardır, Osmanlı yol politikalarının tamamı değildir. 
Yazım sınırlandırılması hangi amaçla yapılırsa yapılsın, konuyu sınırlamak kadar önemli bir başka problem de yapılmış olan sınırlandırmalara yazım aşamasında uymaktır. X Kasabasında Girit Mübadillerinin temel problematik olarak kabul edildiği bir çalışmada metinin üçte birini Girit Savaşları'na ve Osmanlı yönetiminin ilk yıllarına ayırmak yapılan sınırlandırmayı anlamsız kılmaktadır. Keza, Kandiye Fethi (Feth-i Kandiye) konulu bir çalışmada Kandiye seferi anlatıldıktan sonra, "Adanın Yunanistan'a Bağlanması" başlıklı bir bölüm eklemek epistemolojik izahı olmayan ve konunun sınırlandırılmasını delen en çarpıcı örneklerdendir.

Çalışma alanındaki sınırlandırmalar, her zaman planlanan şekilde gitmeyebilir. Çalışmaya başlarken yapılan bir sınırlandırma çalışmanın sonunda farklılaşabilir (Kütükoğlu 1998: 31). Bütün bilim adamlarında olduğu gibi tarihçinin de unutmaması gereken bir konu da sınırlandırdığı olgu ve etkilerin müsaade ettiği kadarıyla sonuçlar çıkarmasıdır. Araştırma konusunu hangi çerçevede sınırlandırırsa sınırlandırsın ulaşacağı sonuç, sınırlandırdığı problematik ile başlayıp bitecektir. Sadece 19. yüzyıla ait $\mathrm{X}$ şehrinin kadı sicillerine bakarak, Türkiyede kapitalizmin kökenlerini bulmak çabası şüphesiz kaynak sonuç sınırlandırması açısından hatalı bir epistemolojik kurgudur. Zira sınırlılıklardan sınırsız genel sonuçlar çıkarmak büyük bir hatadır.

Sonuç olarak bilimsel bir çalışmanın en temel olmazsa olmazlarından birisi çalışmanın sınırlandırılmasının net ve doğru bir şekilde yapılmasıdır. Ne yazık ki Türkiye'deki tarih yazımının da en önemli zaaflarından birisini bu konu oluşturmaktadır. Tarih yazıcılığımızda özellikle son dönemlerde yaşanan bilimsel deformasyon bu sorunun da kaynağıdır. Diğer bilim alanlarında da görünen, tarih yazımında karşılaştı̆ıımız bu zaafın iki temel sebebi olduğunu düşünüyoruz. Bunların ilki epistemolojik yetersizliktir. Üniversitelerin birçok bölümünde yetişen öğrenciler, gerek lisans gerek lisansüstü öğrenimlerinde yeterince bilimsel araştırma yöntemleri ile donatılamamaktadır. Yetişen tarihçi adeta belge okumayı tarih yazmak olarak algılamakta, bilimsel çalışmanın safhaları es geçilmektedir. Bu şekilde yetişen bir tarihçinin yetiştirdiği tarihçi için durum daha da vahim bir hal almaktadır. Tarihin diğer sosyal bilimlerin bir dalı olduğu unutulmakta adeta her konudan ayrık bir ada olarak kurgulanmaktadır. İkinci sebep ise, üniversitelerimizdeki birçok tarihçi tarafından tarih, günümde bile 
kutsal bir alan olarak algılanmaktadır. İdeolojik tutumlar, kimlik ögelerinin bilimsel tutumun önüne geçmesi gibi epistemolojik zaaflar tarih yazımında bilimsel bakışlara ket vurmaktadır. Bu handikapı aşmak sanıldığı kadar zor da değildir aslında. Tüm bilim adamlarının yaptığı gibi bilim yaptığını savunan tarihçi, nesnesi ile arasına bir tarafsızlık koyacaktır. Bu konuda uzağa gitmeden Türk tarihçiliği açısından Suraiya Faroqhi, Mehmet Genç, Oktay Özel ve Özer Ergenç gibi isimler rol model oluşturabilir.

\section{Açıklamalar}

1 Jenkins, bu düşüncenin, David Lowethal'ın The Past is a Foreign Country [Cambridge, 1985] adlı kitabından mülhem olduğunu söylemektedir.

2 Geçmişten Günümüze Girit: Tarih, Toplum, Kültür Uluslararası Sempozyum/International Symposium on Crete From Pastto Present: History, Society, Culture. 16-18 Ekim. 2015. Kuşadası-Aydın. Keza aşağıda verilen örneklerin hepsi yapılmış çalışmalardır fakat çalışmaların tam künyeleri kullanılmamıştır.

3 Yirmi dakikalık konuşma metni, metin okunması olarak 12 punto, 1,5 arlık normal daktilo metni ile en fazla 8 sayfalık bir yazı demektir.

\section{Kaynaklar}

Collingwood, Robin George (2005). Tarihin İlkeleri ve Tarih Felsefesi Üstüne Başka Yazılar. Çev. A. Hamdi Aydoğan. İstanbul: YKY.

Eğilmez, Mahfi (2002). Ekonomi Politikast Sözlüğü. http://www.mahfiegilmez. com/p/ekonomi-sozlugu.html. (Erişim Tarihi:11.02.2017).

Jenkins, Keith (1997). Taribi Yeniden Düşünmek. Çev. B. Sina Şener. Ankara: Dost Kitabevi Yay.

Karasar, Niyazi (2000). Bilimsel Araştırma Yöntemi. Ankara: Nobel Yay.

Kütükoğlu, Mübahat (1998). Tarih Araşttrmalarnda Usûl. İstanbul: Kubbealtı Yay. Langlois, Charles Victor ve Charles Seignobos (1937). Tarih Tetkiklerine Giriş. Çev. Galip Ataç. İstanbul: Kültür Bakanlığı Yay.

Le Bon, Gustav (1932). Tarih Felsefesinin İlmi Esasları. Çev. Haydar Rufat. İstanbul. Reutlinger, Alexander and Matthias Unterhuber (2014). "Thinking about non-universal laws". Erkenntnis 79: 1703-1713. DOİ: http://dx.doi.org/10.1007/ s10670-014-9654-5

Yıldırım, Cemal (2000). Bilim Felsefesi. İstanbul: Remzi Kitabevi. 


\title{
Limitations in Historiography: Ceteris Paribus for the Historian*
}

\section{Nuri Adıyeke*}

\begin{abstract}
Just as in the other sciences, in the science of history too, the researcher must detect the limitations of the problematic that $s /$ he dealt with correctly, and lead the research accordingly. These limitations can be considered in several ways:

I-Limitations based on the objective of writing: Doctorate or book studies, article studies, paper/presentation studies.

II-Limitations based on the source usage: Especially many studies on the Ottoman history is done according to a particular source.

III-Chronological limitations: This is the most common limitation method in historiography. Even though limitations which are explained many times are encountered; sometimes, chronological limitations that have no meaning at all and that are arbitrary can be seen too.

IV-Limitations based on events and cases: In the analysis of the subject defined as problematic, this solution, that is based on only one variable analysis by moving with the assumption that thousands of variables/ impact factors are fixed, will strengthen our ability of analysis theoretically. In our study, the scientific problems caused by limitations that were not possible to be set, and the problems caused by the wrongly-set limitations will be exemplified, and our suggestions on limitations will be presented.
\end{abstract}

\section{Keywords}

History, historian, method, limitation, ceteris paribus.

Date of Arrival: 12 January 2017 - Date of Acceptance: 09 March 2017

You can refer to this article as follows:

Adıyeke, Nuri (2020). “Tarih Yazımında Sınırlandırmalar: Tarihçi İçin Ceteris Paribus”. bilig Journal of Social Sciences of the Turkic World 94: 123-135.

* Asst. Prof. Dr., Dokuz Eylul University, Faculty of Letters, Department of History - İzmir/ Turkey ORCID ID: 0000-0001-8577-2357

nuri.adiyeke@deu.edu.tr 


\title{
Ограничения в историографии: Ceteris Paribus для историка*
}

\section{Нури Адыйеке*}

\begin{abstract}
Аннотация
Как и в других науках, в исторической науке исследователь должен обнаружить ограничения проблем, с которыми он правильно справился, и соответственно провести исследование.

Эти ограничения могут быть рассмотрены несколькими способами:

I-Ограничения, основанные на цели написания: докторское или монографическое исследования, научные статьи, презентации. II-Ограничения, основанные на использовании источника: особенно много исследований по истории Османской империи сделано в соответствии с конкретным источником.

III-Хронологические ограничения: это наиболее распространенный метод ограничения в историографии. Хотя встречаются ограничения, которые объясняются много раз; иногда можно увидеть хронологические ограничения, которые вообще не имеют смысла и являются произвольными.

IV-Ограничения, основанные на событиях и случаях. При анализе объекта, определенного как проблемный, это решение, основанное только на анализе одной переменной, исходя из предположения, что тысячи переменных / факторов воздействия являются фиксированными, усилит нашу способность анализа теоретически.

В нашем исследовании будут проиллюстрированы научные проблемы, вызванные ограничениями, которые невозможно установить, и проблемы, вызванные неправильно установленными ограничениями, и будут представлены наши предложения по ограничениям.
\end{abstract}

\section{Ключевые слова}

История, историк, метод, ограничение, ceteris paribus.

\footnotetext{
* Поступило в редакцию: 12 января 2017 г. - Принято в номер: 09 марта 2017 г.

Ссылка на статью:

Adıyeke, Nuri (2020). "Tarih Yazımında Sınırlandırmalar: Tarihçi İçin Ceteris Paribus”. bilig Журнал Гуманитарных Наук Тюркского Мира 94: 123-135.

** Д-р, Университет Докуз Эйлюль, Филологический факультет, кафедра истории - Измир/ Турция ORCID ID: 0000-0001-8577-2357

nuri.adiyeke@deu.edu.tr
} 